\title{
Ethics and Issues of Secondary Prevention Efforts in Child Sexual
}

\section{Abuse}

Kieran F. McCartan ${ }^{1}$, Hannah L. Merdian², Derek E. Perkins ${ }^{3}$, and Danielle Kettleborough ${ }^{2}$

\author{
${ }^{1}$ University of the West of England, Bristol, UK \\ ${ }^{2}$ University of Lincoln, UK \\ ${ }^{3}$ Royal Holloway University of London, UK
}

Corresponding Author: Kieran F. McCartan, University of the West of England, Frenchay Campus, Bristol, BS16 1WA, UK. Email:

Kieran.mccartan@uwe.ac.uk

Paper published in the International Journal of Offender Therapy and Comparative Criminology. DOI: 10.1177/0306624X17723951 


\begin{abstract}
This article discusses the ethical, practical, and moral issues surrounding secondary prevention efforts of child sexual abuse from a professional and practice-based perspective. Transcripts of a semistructured consultation event with $n=15$ international experts on the secondary prevention of child sexual abuse were analysed using thematic qualitative analysis. The research identified four main critical areas linked to secondary prevention efforts, including, the psychology of selfreporting and disclosure; the interaction with and within existing legal, social, and professional frameworks; the scale and type of an appropriate response; and potential hurdles (i.e., within media, public, politics). The article outlines these areas, highlighting participant perspectives on riskenhancing and mitigating factors for each domain.
\end{abstract}

Keywords: child sexual abuse, prevention, public health approach, treatment, ethics 


\section{Introduction}

In the last few decades, there has been a growing recognition of the depth and extent of sexual violence globally (United Nations Children's Fund [UNICEF], 2014). The increased global sociopolitical recognition of sexual abuse relates to a number of related factors, including increased investment in sexual violence education, increased reporting of historical cases, a growing recognition that anyone can be a victim or perpetrator of sexual violence (including, but not limited to, celebrities, politicians, and most recently, students on college campuses), and an increased media profile of sexual violence (Tabachnick, McCartan, \& Panaro, 2016). Internationally, studies of sexual violence found that the lifetime prevalence of sexual violence ranged from $6 \%$ to $59 \%$ if perpetrated by an intimate partner and from $1 \%$ to $12 \%$ (above 15 years) and $1 \%$ to $21 \%$ (below 15 years) if perpetrated by a nonpartner (World Health Organization, 2014). Research also suggests that sexual violence reporting and conviction rates vary widely between and within countries, especially dependent on the size, culture, and economic status of the country (Jewkes, 2012; UNICEF, 2014).

Currently, there are 49,322 registered sex offenders in England and Wales (College of Policing, personal communication, March 11, 2016), 1,465 registered sex offenders in Northern Ireland (Public Protection Arrangements in Northern Ireland, personal communication, May 20, 2016), and 4,787 registered sex offenders in Scotland (Scottish Government, 2016). Given the scale of the offending population, as well as the fact that it is increasing year on year (O’Sullivan, Hoggett, McCartan, \& Kemshall, 2016), this means that responding to sexual 
abuse becomes very costly; for instance, the annual cost of keeping someone in prison is $£ 33,782$ (Ministry of Justice, 2014), on probation is $£ 2,380$ (Ministry of Justice, 2012), and in a prison-based Sex Offender Treatment Programme is £8,476 (Brookes, Barrett, Netten, \& Knapp, 2013). In addition, research has also documented the lifelong damaging impact on victims of sexual abuse on the physical, mental, reproductive, and sexual health of so many men, women, boys, and girls (Felitti \& Anda, 2009). The short-term and long-term consequences of sexual violence include physical injuries, depression, posttraumatic stress disorder, chronic pain, suicide attempts, substance abuse, unwanted pregnancy, gynaecological disorders, sexually transmitted infections, increased risk for HIV/AIDS, and others (DeGue et al., 2012; Felitti \& Anda, 2009; Harvey, Garcia-Morena, \& Butchart, 2007). Therefore annual estimates of child sexual abuse internationally echo these numbers with figures calculated at US\$124 billion in the United States (Fang, Brown, Florence, \& Mercy, 2012), AUS\$3.9 billion in Australia (Taylor et al., 2008), and £3.2 billon in the United Kingdom (Saied-Tessier, 2014), suggesting that effective prevention has the capacity to not only reduce sexual violence but also to reduce the associated cost. The financial, social, and personal implications of sexual violence provide a strong argument to reframe our understandings of, approaches to, and responses to sexual harm, moving from a criminal justice approach to a public health approach (see Figure $1)$.

Preventive and proactive approaches tend to adopt principles and strategies from the public health arena (McCartan, Kemshall, \& Tabachnick, 2015), and have previously been applied to sexual harm 
prevention (for a comprehensive review of public health approaches to child sexual abuse, see Brown, O’Donnell, \& Erooga, 2011; Letourneau, Eaton, Bass, Berlin, \& Moore, 2014). While it is essential that society responds to the urgency and crisis of sexual violence, a public health focus on prevention expands that response to address the health of an entire population (Centers for Disease Control and Prevention [CDC], 2004; Laws, 2000) and offers a unique insight into ending sexual violence by focusing on the safety and benefits for the largest possible group of people (CDC, 2004; Laws, 2000; McCartan et al., 2015; Smallbone, Marshall, \& Wortley, 2008; Wortley \& Smallbone, 2006). A public health approach allows drawing on multidisciplinary knowledge and perspectives offered by medicine, epidemiology, sociology, psychology, criminology, education, and economics, among others. It is this access to a broad knowledge base that allows the public health approach to effectively respond to a large number of health issues around the world, based on three response levels (Laws, 2000; Wortley \& Smallbone, 2006). These levels include:

- Primary Prevention: Broader approaches that take place before sexual violence has occurred to prevent initial perpetration or victimization (e.g., educating parents how to reduce the risk of sexual victimizations of their children).

- Secondary Prevention: Targeted approaches with "at-risk" populations (e.g., providing an anonymous helpline for men who are concerned about their sexual interest in children).

- Tertiary Prevention: An immediate response after sexual violence has occurred to deal with the immediate consequences of violence (e.g., targeting detected offenders through treatment groups). 
The aim of these levels is to effectively position the appropriate interventions targeted at the appropriate populations, to prevent harmful behaviour and the subsequent negative consequences (see Table 1). In regard to sexual violence prevention, the core aim of these three levels is to stop offending and reduce the impact of sexual violence (McCartan et al., 2015; Smallbone et al., 2008). Increasingly, such approaches are seen as complementary to more traditional criminal justice approaches.

An effective prevention approach thus contains interventions that target (a) behaviours both before and after sexual harm has occurred, and (b) all four levels of the social ecological model (offenders, victims, situations, communities), to be successful in reducing sexually abusive behaviours. However, most child sexual abuse prevention initiatives are aimed at the primary and tertiary levels of prevention, focusing on broad stroke public messages around offending and victimization or reducing reoffending and revictimization, respectively; yet, these fail to focus on specific "atrisk” populations, who may benefit from more targeted interventions beyond general deterrence/resilience building but who do not (yet) qualify for interventions at the tertiary level.

Internationally, there has been an increase in projects oriented toward this group of potential offenders and at-risk individuals, such as the German Prevention Project Dunkelfeld, who provide anonymous assessment and treatment for men who have self-identified as sexual harm perpetrators and/or pedophiles. The U.S. Help Wanted provides a web-based prevention intervention for adolescents who are sexually attracted to children, and the Stop-it-now!-Helpline in the United Kingdom and the Netherlands provide confidential support for sexual 
harm prevention. While a shift toward a public health approach of sexual harm prevention is in line with the mission statements of professional organizations (for instance, Association for the Treatment of Sexual Abuse, National Society for the Prevention of Child Cruelty [NSPCC], Lucy Faithfull Foundation, Safer Living Foundation) and the targeted individuals themselves (e.g., see Merdian, Perkins, Dustagheer, \& Glorney, in press), currently what is missing from the literature is a review of the ethical and professional frameworks that guide secondary harm-prevention efforts.

The current article aims to understand professionals' attitudes to the risks posed by, benefits of, and the ethics of secondary prevention efforts relating to child sexual abuse in the United Kingdom. The United Kingdom was selected because of the growing discussions around public health approaches to child sexual abuse occurring here (Brown \& Saied-Tessier, 2015) and recent moves toward the development and implementation of secondary prevention programmes through the Lucy Faithfull Foundation (Gillespie et al., 2016), Safer Living Foundation (Safer Living Foundation, 2016), and Circles South West (Circles South West, 2016).

\section{Method}

\section{Study Design}

The purpose of this study, particularly the discussion groups, was to inform current conversations, discussions, and debates ongoing in the research, practice, and policy communities surrounding the secondary prevention of child sexual abuse. The current study utilised discussion groups to inform the study and offer a real-world grounding to the current debate; it was not the aim of the study to provide a 
definitive answer, but rather to contextualize an informed debate. Therefore, the current piece is qualitative in nature, consisting of a single roundtable table discussion $(n=15)$, followed by three smaller discussion groups ( $n=5$ each) with leading practitioners, authors, and researchers in the area. The conversations were generally unstructured, which allowed discussants to give in-depth, reflective, and personalised responses (Bryman, 2008; Robson \& McCartan, 2016). As discussions around secondary prevention are in their early stages in the United Kingdom, we invited four representatives to provide opening statements on the issue. There was no further guidance provided on the content or themes to be discussed on the tables, to allow discussants to give a range of responses, to freely debate the issue, and to consider the reality and impact of secondary prevention efforts within their research and practice experience. Due to the exploratory nature of this research, a qualitative research design that allows to capture individual experience and perception was considered the best fit for the current research aim.

\section{Participants/Discussants}

Overall, 15 discussants from four countries (Germany, Ireland, the United Kingdom, the United States) attended the roundtable, including researchers, policy makers, government representatives, criminal justice professionals, practitioners working in child protection, and health care professionals. Through snowball sampling (Robson \& McCartan, 2016), the discussants were recruited from different backgrounds, including professionals (including representations from the U.K. Government, National Health Service [NHS] trusts, Probation Service, and Prison Service), stakeholders (including representations from the Prevention Project Dunkelfeld and the Lucy Faithfull 
Foundation), and academics (including representations from the University of the West of England and the University of Leeds); all discussants were selected because of their research, role, or practice in the field. As part of the recruitment strategy, the discussants were informed that the discussion groups would not be recorded verbatim; instead there would be note-takers at every table. Consequently, we cannot draw on direct quotes, but aimed to capture through the notes the overall sense and direction of the discussion. This process was chosen to reassure discussants, given the emergent and sensitive nature of this topic as well as the fact that in some instances the discussants' home organization had not yet provided an official stance and that they may feel that by having a recorded statement they were unofficially giving said statement. All discussants were White, with a 50:50 male: female ratio. Three speakers were selected to provide an opening statement; a fourth speaker was added via video-conferencing. Discussants were seated on three separate tables; membership of each discussion group was based on a varied mix of academics, policy makers, practitioners, one speaker, and a member of the research team.

\section{Procedure and Materials}

The roundtable discussion was aimed to elicit a better understanding of secondary harm-prevention efforts and to develop an initial ethics framework. After the introductions, the discussions started with statements from the four speakers, who presented secondary-level child sexual abuse prevention projects they were involved in, across Germany, the United States, and the United Kingdom. The content of the statements from the four speakers was selected as a result of preliminary discussions between themselves and the research team to focus on the 
most pressing and topical issues in the field of secondary prevention of sexual abuse; the four topics were not meant to be all encompassing, but rather a general overview and a series of open remarks. The four statements focused on (a) working with populations at risk of perpetration; (b) current understandings of sex, sexuality, and sexual abuse; (c) current national and international practices, as well as new developments, in preventing child sexual abuse; and (d) practical considerations for professionals in the field of child sexual abuse prevention. This was followed by a question-and-answer session, followed by three smaller subgroup discussions on the topics at hand, comprising semistructured discussions on the ethical issues linked to the secondary prevention of child sexual abuse. The prompt questions given to each discussion group were developed out of the existing literature on secondary prevention, current debates in the field (locally, nationally, and internationally) and issues raised by the four speakers. Each small group was chaired by a member of the research team whose role was to make sure that the discussions stayed on track, were coherent, addressed the required issues, at times challenge the discussants, make research notes and feed the results of the discussion back to the main group. As the research group chairs were making notes and recording the contents of the group discussions, there were no audio recordings made. The aim of each focus group was to have a rounded main discussion, chaired by one member of the research team; the final discussion was audio-recorded and provided the basis for theme extraction and analysis. The roundtable discussion and parallel subgroup discussions lasted approximately two hours.

\section{Data Analysis}


This study used Thematic Analysis (Flick, 2009) to examine the data. This approach was selected because of its fit with the exploratory aims and objectives of the current research (Krippendorff, 2004). This method is particularly useful for roundtable discussions and small group activities, which have the potential for a multitude of perspectives, debates, and varying attitudes to be displayed, both between and within each group in the sample. The research team used an inductive approach to thematic analysis of the data, as the research is based on an interpretivist epistemology and a constructivist ontology, which allowed themes to emerge directly from the data. Given the unique issues posed by discussion group research (Robson \& McCartan, 2016) and due to the type of data that was collected in this research (summative notes rather than transcripts), a detailed thematic analysis (Braun \& Clarke, 2006) could not be conducted. Instead, the outputs form each focus group and the main discussion were treated as a separate document (i.e., a summary sheet) and fed into the analysis (Bowen, 2009). The current study thus employed an adjusted version of Braun and Clarke’s (2006) approach (see Table 2).

Although we completed all six stages of Braun and Clarke's (2006) approach, Sections 3, 4, and 6 were adjusted toward the limited volume of data (the notes and summaries are shorter and less detailed than discussion transcriptions) and the different nature of the data (the notes and summaries were broader, less precise, and lacked attributable quotes compared with transcriptions). Throughout the qualitative data analysis, care was taken to ensure that the themes established themselves (Hycner, 1985); emerging themes were verified through interrater reliability within the research team; any disagreement 
between researchers was discussed until agreement was reached. By doing so, it was ensured that each code and the resulting analysis was coherent, cross-referenced to the other themes, and made sense in the overall data analysis. All the themes were considered in terms of how they related to each other, the overall findings from the research, and the existing literature.

\section{Results}

Overall, four themes concerning the benefits and risks surrounding the ethics of secondary harm-prevention efforts emerged from the speakers' and discussants' contributions. These referred to (a) the psychology of self-reporting and disclosure; (b) the existing legal, social, and professional frameworks; (c) the scale and type of an appropriate response; and (d) potential hurdles (i.e., within media, public, politics) and related consequences for the individual and professional stakeholders. Given the number of discussants, the nature of discussion groups, and the nature of the way that the qualitative data were recorded, the "Results" section will focus on the main points of discussion and not the quotes from individual discussants, to avoid identification of individual members.

\section{Psychology of Self-Reporting and Disclosure}

The first theme identified from the discussants' contributions refers to issues surrounding self-reporting and offence disclosure, linked to issues arising with the provision of confidential support avenues; within this theme, discussants referred to the management of helpseeking behaviours, and the tension between the offenders' need for support and managing the presented risk to themselves and others. 
The discussants' discussion initially focused on existing secondary-level prevention avenues (e.g., anonymous helplines or confidential treatment groups) for potential perpetrators or individuals who are awaiting criminal justice outcomes (postarrest but preconviction). Here, discussants identified several inhibitions to helpseeking behaviours on part of the offending individuals. Professionals working with online offenders described how many reported that they had already attempted to stop their urges before committing an offence, stopping their ongoing offending, or had sought professional help, prior to being arrested; however, many clients had reported they felt deterred from seeking help prior to their criminal justice engagement because they were unaware of available support avenues, hesitant to search for them online, and feared the consequences of disclosing their offending due to uncertainty about the consequences.

In addition to self-managed help-seeking, the roundtable discussants recognised a number of system-related issues, mainly concerning the management of the balance between professionals' reporting obligations within the criminal justice system (e.g., what can be disclosed without being reported? At what point do offending behaviours need to be reported?) and the therapeutic needs of the individuals (e.g., supporting desistance from offending behaviour, managing the consequences of arrest and disclosures). Discussions highlighted the tension between the client's risk versus the client's needs as a key factor when considering prevention approaches; discussants reported that the majority of clients they had talked to insisted they were unlikely to seek help, either pre or post offending, if their identity, potential or current behaviour, or discussions had to be 
disclosed to the criminal justice system. These findings are in line with research indicating that people convicted of sexual crimes are aware of the stigma linked to their offending behaviour and that they fear any outcome that results in their information being passed on (Hudson, 2005; Jahnke, Schmidt, Geradt, \& Hoyer, 2015; McCartan, 2016).

As well as potential perpetrators fearing social stigmatisation and alienation, discussants who work in offender management also referred to a "personal alienation" experienced by the offenders. Many potential or current offenders had felt personally alienated before and throughout their offending, as a potentially large part of their identity and daily lives (i.e., their sexual fantasies, fears, or sexual behaviours) had to be kept "secret" from their families or other potential sources of social support. Discussants reported that these individuals' stories “just poured out of them” once a safe space for disclosure was provided, and suggested that the provision of such a safe conversational space may in itself have a preventive function for some offenders. This perhaps argues for the provision of confidential support avenues, where individuals can discuss their fantasies and viewing behaviours in a proactive and deterrence-orientated way. This finding parallels existing empirical findings, such as reports from potential perpetrators or current offending individuals involved in VirPed and the "this American life" interviews (Malone, 2014), what is known from sex offender treatment groups (Gillespie et al., 2016), and community treatment models like Circles of Support and Accountability (McCartan, 2016). However, discussants were also aware of the risk management elements of this, given the opportunities for potential or current offenders to minimise the extent of their offending in their initial disclosures and the potential 
effects of normalising offending-related fantasies and behaviours (e.g., see Beier et al., 2014).

In summary, discussants identified that effective secondary harm-prevention efforts need to have a clear outreach plan, to reach first-time and potential offenders despite the reported inhibitions to help-seeking, and need to consider a system that effectively responds to the needs versus risk dilemma discussed above. With regard to the former, a media-supported campaign by the Lucy Faithfull Foundation targeting individuals accessing and downloading child sexual abuse material showed approximately two million hits in eight months by individuals concerned about their behaviour (Sheath, 2016), with promising results (Gillespie et al., 2016). However, such media-based campaigns may not reach more hidden parts of the Internet or file sharing/email systems, which are commonly used to share illegal images of children (Taylor \& Quayle, 2003). Overall, this theme reemphasised the need for anonymous support avenues for people at risk of committing a child sexual offence; but, in doing so, it revealed that the opportunity to engage in support is limited by its availability, its accessibility, and the individual's self-directed help-seeking behaviour. Thus, issues to take forward for the development of an ethical framework refer to offender engagement, community safety, and risk management issues.

\section{Working Within the Existing Legal, Social, and Professional}

\section{Framework}

The second theme that emerged from the discussants' discussions referred to where secondary prevention efforts would be placed within the existing legal, social, and professional frameworks, 
and how this informs and shapes the practicalities of their implementation.

With the United Kingdom as the national point of focus, discussants' discussion mainly concerned the legal structures in the United Kingdom, complemented by experience from the international discussants. Discussants reflected on a change of direction and approach in the United Kingdom toward earlier prevention, especially in relation to the use of child sexual exploitation material as highlighted by a senior police officer publicly stating that "we are not going to be able to arrest our way out of it” (Evans, 2014). Here, much of the debate was focused on the German Prevention Project Dunkelfeld (Beier et al., 2014; Beier et al., 2009), which offers confidential support to individuals who are concerned about their thoughts and actions related to a self-identified sexual interest in children, and the ethical and practical barriers such an approach may face in the United Kingdom. Generally, the Prevention Project Dunkelfeld shows positive (although early and emerging) results in the treated group, as opposed to the nontreated group, with improved emotional functioning, sexual selfregulation, and decreased cognitive distortions (Beier et al., 2009; Beier et al., 2015). However, the Prevention Project Dunkelfeld is placed within a different legal context that does not necessarily require compulsory reporting of (potential) victims. Discussants in the roundtable discussion raised the issue of mandatory reporting and the rights of (identified/unknown) victims as the most critical concern, especially considering the legal framework in the United Kingdom that requires to refer/report if a child is at immediate risk; they also challenged that mandatory reporting is less clear in respect to historical 
allegations and past risk of offending (British Psychological Society [BPS], 2015) and reflected on the ongoing debate about the nature of mandatory reporting (Appleton, 2016; Doward, 2016; NSPCC, 2014). Some discussants pointed to the need for clear briefings, both to the support providers and recipients, in terms of what questions would be asked, what information would be recorded, what information would be needed to be disclosed to criminal justice, and general clarity of the therapeutic relationship/contract and session outcomes. However, discussants queried the gray area surrounding this, debating if it is a professional's duty to probe for information that may protect (potential) victims and/or indicate additional or potential offending behaviour, yet again referring to the ethical conflict between protecting the individual from self-incrimination versus protecting any potential or existing victims from (further) harm.

In line with these considerations, discussants also revisited the issue of identifying suitable avenues for prevention. For example, most existing U.K.-based interventions, such as information about Inform Plus (the Lucy Faithfull Foundation) is available online, and thus, initially, no identifying information about the accessed individuals is collected. Discussants suggested the importance of exploring other health-related interventions and their contact avenues to seek specific ideas about how information is taken and shared with at-risk health populations.

\section{Scale and Type of Response}

The third emerging theme referred to the scale, nature, and availability of secondary prevention services; specifically, the type of medium used and its accessibility. Discussants discussed the availability 
of online and offline services for populations at risk of sexual offending or those offending individuals who are not yet known to the criminal justice system; overall, discussants felt that the medium through which help was sought and how it was accessed presented two crucial issues.

In respect to the provision of online help and support, discussants felt that the wide availability and accessibility of the Internet, the speed of the Internet, and individuals' ability to understand and use it were important considerations. Discussants reflected that current support systems mainly referred to initial points of contact and wondered if help-seeking individuals might also extend their engagement, for example, through online support forums or online treatment modules. However, a number of questions were raised, concerning a secure platform to access the material, what search terms would be used to identify them, how anonymity and confidentiality could be guaranteed, and how the legitimacy of the site, programme, and staff could be verified and maintained. Discussants further discussed whether Internet sites would have the appropriate security so that user information could not be accessed, hacked, or indirectly exposed, which is particularly salient given the sensitive and legally, as well as socially, problematic nature of disclosures. For example, Inform Plus (the Lucy Faithfull Service) anonymises ISPs when the individual is first accessing the material on their site, but cannot do so when people log in to complete their online modules (Sheath, 2016).

In regard to offline help and support, the discussants identified a range of issues different to those raised for online support, with the exception of how the service is advertised and accessed. The discussants were concerned that the provision of physical/face-to-face 
services would result in a "postcode lottery" for the availability of secondary prevention efforts, similar to existing offender management, health care provision, and treatment availability. Thus, areas with larger populations, higher crime rates, more funding, and/or more responsive providers might be able to provide an in-person service, whereas other, more remote, or less affluent areas (which may also have poor access to the Internet or slower connections) would not have access to these services.

A related issue raised referred to the type of service provider: Could these services be offered through the NHS—at hospitals, GP surgeries, or health centres? If so, how would any potential safeguarding issues be resolved? Is the provision of these services a national governmental decision or a local health board decision? Discussants also discussed ethical issues linked to this type of service provision: How would reporting/recording work? Would referrals be involved? Would individuals, once committed, be able to withdraw? How would safeguarding of the client's identity be ensured once the provider has met the client?

Overall, this theme built onto the previous themes by focusing on the actual nature of support systems, and the willingness of the offending/at-risk individual to invest in structured support from unfamiliar providers. These aspects point to the need for an ethical framework to consider the practical aspects of online versus offline support systems, and the implications of each response possibility. Media, Public, and Political Hurdles

All the discussants raised that a major challenge, ethical or otherwise, facing any form of secondary prevention with individuals at 
risk of or currently engaged in sexual offending was dealing with the public relations element of it. The discussants were unsure how any intervention would be perceived by the public, media, or policy makers; discussants expressed concerns that such interventions would be perceived as safeguarding sex offenders at the expense of victims, and that the focus on (long-term) child protection would not be clearly accessible to the external stakeholders. Here, the discussants discussed the experiences of a U.S. campaign; they reported stronger public support for their focus on youth, rather than on adult offenders, based on the enhanced public endorsement that youth offenders are more likely to change and rehabilitate. This further emphasised the benefits of a public health, developmental, and life course approach to deterrence and rehabilitation rather than a unidimensional risk management approach.

Discussants discussed that starting with youth offenders would also allow them to build on already existing primary prevention campaigns aimed at youths (i.e., sexual education in schools, bystander intervention programmes, safe touch, discussions around pornography and healthy sexual relationships), providing a clear narrative between these prevention approaches and making online and offline interventions more straightforward; this would usefully link with the nature of youth environments as well as existing support structures in the United Kingdom. The use of secondary prevention programmes with young people raises many safeguarding and ethical issues for the youths themselves and/or their families, but these are not uncommon in the arena of youth work, social work, or youth offending. 
Regardless of whether the at-risk offender population is adult or youth, male or female, White or ethnically diverse, the consistent identified ethical difficulty was "getting the right message across"; that is, identifying the right message (e.g., "Stopitnow!" for Stopitnow-UK and Wales; "Don’t Offend” for the Prevention Project Dunkelfeld), using the correct language, utilising facts appropriately, and "selling it" to the audience. Discussants were generally supportive of a move away from a purely criminal justice approach to sexual harm and toward a public health/health-based approach (see Figure 1) and referred to successful examples of this approach, such as drug usage management and deterrence campaigns (Stevens, 2011). However, the ethical dilemma posed by this approach is how to demonstrate its effectiveness not only for the offender but also for the victim/potential victims. The discussants all agreed that it would be more effective to provide support and interventions for populations at the pre-offence stage than to focus all resources at the postoffence stage.

The discussants all felt that they had a role to play in engaging with the media, to ensure that the media is aware of the differentiation between offending behaviour and a diagnosis of paedophilia, and with regard to the positive impact of treatment, rehabilitation, and prevention. The discussants emphasised that professionals need to engage more proactively with the media beyond news media; for example, TV programmes are critical media to communicate with the public (see, for instance, EastEnders storyline concerning the fictional character Mark Fowler who was HIV positive). The discussants further reinforced the need for experts to engage constructively in public dialogue and to proactively use media opportunities as the central 
importance of public criminology in changing the social justice landscape (Loader \& Sparks, 2010).

In summary, this last theme alerted to the ethical issues of community, media, and political engagement and related decisionmaking. Discussants communicated that the introduction of secondary prevention efforts may require a staged effort (e.g., from youth toward adult populations) and that a change in the social landscape will take time, given that policy makers, the public, and the media need to understand the topical relevance of this issue (McCartan et al., 2014; Tabachnick et al., 2016).

\section{Conclusion}

\section{Summary of Findings}

The current study explored the ethics and issues surrounding secondary prevention efforts of child sexual abuse offending, with a specific focus on the legal and professional framework of the United Kingdom. The study was based on a roundtable discussion with different stakeholders, including researchers, policy makers, government representatives, and practitioners working in child protection. Four chairs were invited who had direct experience of secondary prevention systems. Overall, four themes emerged from the discussants' discussions: (a) The psychology of self-reporting and disclosure, and the need to consider offender engagement, community safety, and risk management issues; (b) the existing legal, social, and professional frameworks, and how this informs and shapes the practicalities of their implementation; (c) the scale and type of an appropriate response, concerning the practical aspects of online versus offline support systems, the implications of each response possibility, 
and the willingness of the at-risk individual to engage in them; and (d) the potential hurdles (i.e., within media, public, politics) of these interventions. The discussants' views on the secondary prevention efforts toward child sexual abuse offending reinforced the need to consider the whole spectrum of Cohen and Swift's (1990) Prevention Model (see Figure 2), normally used in public health campaigns (McCartan et al., 2014; Tabachnick et al., 2016), as a mechanism to creating a holistic, multifaceted, and multiagency prevention approach. The findings from this study reinforce the need to broaden the criminal justice approach toward a more public health-orientated, preventive approach (McCartan et al., 2014; Tabachnick et al., 2016). Such an approach would open broader societal conversations on prevention, support, ethics, intervention, partnership working with communities, and education on a range of sexual harm-related issues. In reframing the conversation, we can hopefully add to the prevention of child sexual abuse in proactive ways that allow us to engage with "at-risk" individuals and victim populations more proactively and practically.

Overall, this discussion group research and debate highlighted a number of emerging and potential ethical issues linked to the introduction and maintenance of secondary prevention of child sexual abuse, namely,

- Focusing on individual safeguarding, protection, anonymity, and confidentiality;

- Maintaining and updating professional ethical guidelines, standards, and protections;

- Focusing on public protection and community risk management; 
- Engaging in public, media, and policy discourses as well as how best to discuss secondary prevention in the public domain;

- Consideration of different at-risk groups in the implementation process;

- Considering the types of secondary prevention offered, their location, accessibility, availability, and utility;

- Integrating these efforts into the current legal frameworks, policy, practice, and professional standards, and considering whether they lend themselves to a public health, preventive approach.

- Considering the interaction of all these aspects.

\section{Limitations}

As this was a small-scale, exploratory study, there are some limitations which affected its outcomes and impact. The study was conducted with a self-selected sample that therefore may not be representative of the field as a whole; one particular shortcoming is the lack of a victim or offender representative in the research. The mode of data collection (i.e., summative notes; see Table 2) likely affected the quality of the data, the strength of the data analysis, the interrater reliability, and, consequently, the strength as well as reach of the data. Future research should aim to refine the method in terms of sampling (larger and more broadly defined discussants), methodology (semistructured interviews or a Delphi study), data collection (recording the discussions followed by a full transcription and analysis), data analysis (utilising quotes, stronger interrater reliability, and potentially include a quantitative element to develop a broader professional and societal understanding of secondary prevention), and outcomes (having 
more defined and generalizable outcomes and/or recommendations). However, the current study was designed to act as an initial platform for discussions around the ethics of secondary prevention and to spark further debate resulting from it.

\section{Way Forward}

Based on these discussion outcomes, we have developed some preliminary thoughts on how to address the ethical issues linked to secondary prevention, focusing on the development of

- A standardised approach to secondary prevention across the United Kingdom: All programmes should follow a similar model that is based on evidence-based practice, both from forensic research and drawing on other health interventions with at-risk populations.

- Standardised guidelines based on existing protocols within the public health sphere relating to working with at-risk populations, dealing with anonymity, confidentiality, data sharing, and safeguarding.

- A clear disclosure protocol for individually disclosed information based on risk, level, and type of disclosure, and accountability, communicated in writing and at the point of commencement of the interaction between the individual and the service provider.

- A complementary approach of online and offline services to increase the likelihood of engagement, with system-appropriate variations on safeguarding, confidentiality, anonymity, and data sharing agreements. It is crucial to consider that accessibility of these services should not disadvantage the service user. 
- A guidance document for third-party organizations, the media, public, and policy makers, to communicate the narrative underlying this approach.

This article highlights the complex nature of introducing secondary prevention efforts of child sexual abuse in general, and with a specific focus on the United Kingdom, and discusses some of the ethical issues related to it. The main issues raised by this study are some tangible steps that service providers and stakeholders can take when considering secondary prevention efforts. A secondary issue raised by this study is that it might be useful to publicly discuss the advertisement and implementation of this approach; to embed the interventions into a positive public health and harm-prevention framework; and to normalise this approach for the multiple communities that exist within the United Kingdom. This study advocates that secondary prevention can usefully complement, and in some cases provide, a viable alternative to a criminal justice approach, which is rooted in a public health model.

\section{Declaration of Conflicting Interests}

The author(s) declared no potential conflicts of interest with respect to the research, authorship, and/or publication of this article.

\section{Funding}

The author(s) received no financial support for the research, authorship, and/or publication of this article. 


\section{References}

Appleton, J. (2016, June). “Mandatory reporting” of suspected child abuse is a mad, bad idea. The Spectator. Retrieved from http://www.spectator.co.uk/2016/06/mandatory-reporting-ofsuspected-child-abuse-is-a-mad-bad-idea/

Beier, K. M., Grundmann, D., Kuhle, L. F., Scherrner, G., Konard, A., \& Amelung, T. (2014). The German Dunkelfeld project: A pilot study to prevent child sexual abuse and the use of child abusive images. Journal of Sexual Medicine, 12, 529-542. doi:10.1111/jsm.12785

Beier, K. M., Grundmann, D., Kuhle, L. F., Scherner, G., Konrad, A., \& Amelung, T. (2015). The German Dunkelfeld Project: A pilot study to prevent child sexual abuse and the use of child abusive images. The Journal of Sexual Medicine, 12(2), 529-542. doi: 10.1111/jsm.12785

Beier, K. M., Neutze, J., Mundt, I. A., Ahlers, C. J., Goecker, D., Konrad, A., \& Schaefer, G. E. (2009). Encouraging selfidentified pedophiles and hebephiles to seek professional help: First results of the Prevention Project Dunkelfeld (PPD). Child Abuse and Neglect, 33, 545-549.

Bowen, G. A., (2009). Document analysis as a qualitative research method. Qualitative Research Journal, 9(2), 27-40.

Braun, V., \& Clarke, V. (2006). Using thematic analysis in psychology. Qualitative Research in Psychology, 3, 77-101.

British Psychological Society. (2015). DCP guidance document on the management of disclosure of historic child sexual abuse.

Retrieved from http://www.google.co.uk/ 
url?sa=t\&rct=j\&q=\&esrc=s\&source=web\&cd=5\&cad=rja\&uac $\mathrm{t}=8 \&$ ved $=0$ ahUKEwjUxdD-

7IHOAhUnB8AKHTdHA74QFghIMAQ\&url=http\%3A\%2F\% 2Fwww.bps.org.uk\%2Fsystem\%2Ffiles\%2FPublic\%2520files \%2FPolicy\%2Fhistorical_abuse_draft_for_comment_18_june_ khadj_doc.docx\&usg=AFQjCNHK1D1bXitBa8o3Yro93YGvC aWFwg\&sig2=YX2h8iCiuW5bsh4ZtzLYWQ

Brookes, N., Barrett, B., Netten, A., \& Knapp, E. (2013). Unit costs in criminal Justice. Personal Social Services Research Unit, University of Kent, \& London School of Economics. Retrieved from http://www.pssru.ac.uk/archive/pdf/dp2855.pdf

Brown, J., O’Donnell, T., \& Erooga, M. (2011). Sexual abuse: A public health challenge. London, UK: National Society for the Prevention of Cruelty to Children.

Brown, J., \& Saied-Tessier, A. (2015). Preventing child sexual abuse: Towards a National strategy for England. London, UK: National Society for the Prevention of Cruelty to Children. Bryman, A. (2008). Social research methods (3rd ed.). Oxford, UK: Oxford University Press.

Centers for Disease Control and Prevention. (2004). Sexual violence prevention: Beginning the dialogue. Atlanta, GA: Author.

Circles South West. (2016, June). Change, continuity and growth for CSW. Retrieved from. http://www.circlesuk.org.uk/images/documents/CSW-Newsletter-June2016.pdf Cohen, L., \& Swift, S. (1999). The spectrum of prevention: developing a comprehensive approach to injury prevention. Injury Prevention, 5(3), 203-207. 
DeGue, S., Holt, M. K., Massetti, G. M., Matjasko, J. L., Tharp, A. T., \& Valle, L. A. (2012). Looking ahead toward community-level strategies to prevent sexual violence. Journal of Women's Health, 21, 1-3. doi:10.1089/jwh.2011.3263

Doward, J. (2016). Failure to report signs of child abuse "should be made a criminal offence.” The Guardian. Retrieved from https:/www.theguardian.com/society/2016/may/28/failure-toreport-child-abuse-criminal-offence

Evans, M. (2014). Thousands of paedophiles will escape justice, crime chief admits. The Telegraph. Retrieved from http://www.telegraph.co.uk/news/uknews/crime/11174715/ Thousands-of-paedophiles-will-escape-justice-crime-chiefadmits.html

Fang, X., Brown, D. S., Florence, C. S., \& Mercy, J. A. (2012). The economic burden of child maltreatment in the United States and implications for prevention. Child Abuse \& Neglect, 36, 156165.

Felitti, V., \& Anda, R. (2009). The relationship of adverse childhood experiences to adult medical disease, psychiatric disorders, and sexual behavior: Implications for healthcare. In R. Lanius \& E. Vermetten (Eds.), The hidden epidemic: The impact of early life trauma on health and disease (pp. 77-86). Cambridge, UK:

Cambridge University Press.

Flick, U. (2009). An introduction to qualitative research (4th ed.). London, England: SAGE.

Gillespie, S. M., Bailey, A., Squire, T., Carey, M. L., Eldridge, H. J., \& Beech, A. R. (2016). An evaluation of a community-based 
psycho-educational program for users of child sexual exploitation material. Sexual Abuse: A Journal of Research and Treatment. Advance online publication.

doi:10.1177/1079063216639591

Harvey, A., Garcia-Morena, C., \& Butchart, A. (2007, May 2-3).

Primary prevention of intimate-partner violence and sexual violence. Background paper for WHO expert meeting, World Health Organization, Geneva, Switzerland.

Hudson, K. J. (2005). Offending identities: Sex offenders' perspectives of their treatment and management. Uffculme, UK: Willan Publishing.

Hycner, R. H. (1985). Some guidelines for the phenomenological analysis of interview data. Human Studies, 8, 279-303.

Jahnke, S., Schmidt, A. F., Geradt, M., \& Hoyer, J. (2015). StigmaRelated Stress and Its Correlates among Men with Pedophilic Sexual Interests. Archives of Sexual Behavior, 44(8), 21732187.

Jewkes, R. (2012). Rape perpetration: A review. Pretoria, South Africa: Sexual Violence Research Initiative.

Krippendorff, K. (2004). Content analysis: An introduction to its methodology (2nd ed.). London, England: SAGE.

Laws, D. R. (2000). Sexual offending as a public health problem: A North American perspective. Journal of Sexual Aggression, 5, $30-44$.

Letourneau, E. J., Eaton, W. W., Bass, J., Berlin, F., \& Moore, S. G. (2014). The need for a comprehensive public health approach to 
preventing child sexual abuse. Public Health Reports, 129, 222228.

Loader, I., \& Sparks, R. (2010). Public criminology? London, UK: Routledge.

Malone, L. (2014, April). Help wanted. On This American life [Audio]. Retrieved from http:/www.thisamericanlife.org/radioarchives/episode/522/tarred-and-feathered?act=2

McCartan, K. (2016). Circles of support and accountability social impact evaluation: Final report (Project report). London, UK: Circles UK.

McCartan, K. F., \& McKenzie, N., (2014). Restorative justice, community action and public protection. In Maile, S., \& Griffiths, D. (Eds.) Public Engagement and Social Science. Bristol, UK: Policy Press.

McCartan, K., Kemshall, H., \& Tabachnick, J. (2015). The construction of community understandings of sexual violence: Rethinking public, practitioner and policy discourses. Journal of Sexual Aggression, 211, 100-116.

Merdian, H., Perkins, D., Dustagheer, E., \& Glorney, E. (in press).

Development of a case formulation model for users of child sexual exploitation material. International Journal of Offender Therapy and Comparative Criminology.

Ministry of Justice. (2012). Probation trust unit costs: Financial year 2011-12 (revised). London, England: Author. Retrieved from https://www.gov.uk/government/uploads/system/ uploads/attachment_data/file/218335/probation-trust-unit-coststables-11-12.pdf 
Ministry of Justice. (2014). Costs per place and costs per prisoner: National offender management service annual report and accounts 2013-14. London, England: Author. Retrieved from https://www.gov.uk/government/uploads/system/uploads/attach ment_data/ file/367551/cost-per-place-and-prisoner-2013-14-summary.pdf

National Society for the Prevention of Cruelty to Children. (2014). Exploring the case for mandatory reporting: A summary of a roundtable hosted by the NSPCC. Retrieved from https://www.nspcc.org.uk/globalassets/documents/informationservice/exploring-case-mandatory-reporting-roundtablesummary.pdf

O’Sullivan, J., Hoggett, H., McCartan, K. F., \& Kemshall, H. (2016). Understandings, implications and alternative approaches to the use of the sex offenders register in the UK. Irish Probation Journal, 13, 84-101.

Robson, C., \& McCartan, K. (2016). Real world research (4th ed.). Chichester, UK: John Wiley.

Safer Living Foundation. (2016). The safer living foundation prevention project. Retrieved from http://saferlivingfoundation.org/prevention/

Saied-Tessier, A. (2014). Estimating the cost of child sexual abuse in the UK. London, England: National Society for the Prevention of Cruelty to Children. Retrieved from http://www.nspcc.org.uk/globalassets/documents/researchreports/estimating-costs-child-sexual-abuse-uk.pdf 
Scottish Government. (2016). Multi-agency public protection arrangements (MAPPA) in Scotland (National Overview Report 2014 / 15). Author. Retrieved from www.gov.scot/ Resource/0048/00488223.docx

Sheath, M. (2016, June). Secondary prevention and the Lucy Faithfull Foundation. Paper presented at NSPCC Rebuilding Childhood annual conference, Edinburgh, UK.

Smallbone, S., Marshall, W. L., \& Wortley, R. (2008). Preventing child sexual abuse: Evidence, policy and practice. Devon, UK: Willan Publishing.

Smallbone, S., \& Rayment-McHugh, S. (2013). Preventing youth sexual violence and abuse: Problems and solutions in the Australian context. Australian Psychologist, 48, 3-13.

Stevens, A. (2011). Drugs, crime and public health: The political economy of drug policy. Oxon, UK: Routledge.

Tabachnick, J., McCartan, K., \& Panaro, R. (2016). Changing course: From a victim/offender duality to a public health perspective. In R. Laws \& W. O’Donoghue (Eds.), Treatment of sex offenders: Strengths and weaknesses in assessment and intervention (pp. 323-342). London, UK: Springer.

Taylor, M., \& Quayle, E. (2003). Child pornography: An internet crime. Hove, UK: Brunner-Routledge.

Taylor, P., Moore, P., Pezzullo, L., Tucci, J., Goddard, C., \& De Bortoli, L. (2008). The cost of child abuse in Australia. Melbourne: Australian Childhood Foundation and Child Abuse Prevention Research. 
United Nations Children’s Fund. (2014). Hidden in plain sight.

Retrieved from http://files.unicef.org/publications/files/Hidden_in_plain_sight_ statistical_analysis_EN_3_Sept_2014.pdf

World Health Organization. (2014). Global status report on violence prevention 2014. Retrieved from http://www.who.int/violence_injury_prevention/violence/status _report/ 2014/report/report/en/

Wortley, R., \& Smallbone, S. (Eds.). (2006). Situational prevention of child sexual abuse. Monsey, NY: Criminal Justice Press. 
Figures 


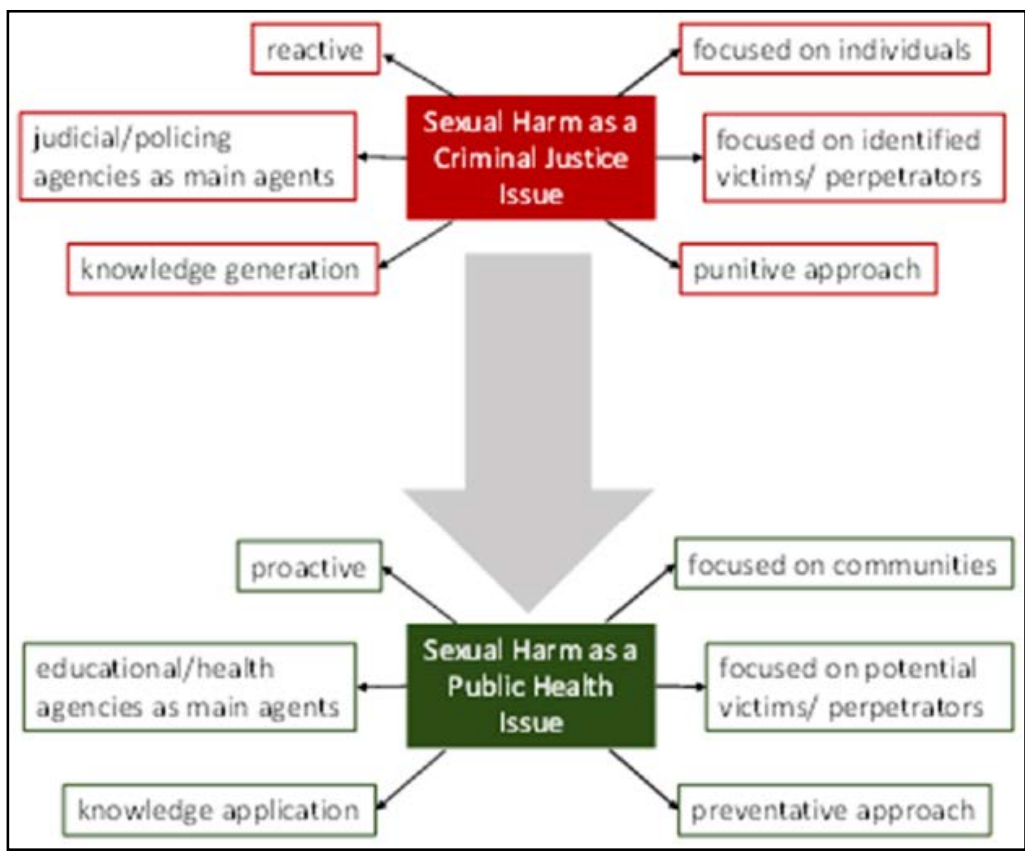

Figure 1. Schematic presentation of sexual harm as a criminal justice versus public health issue. 


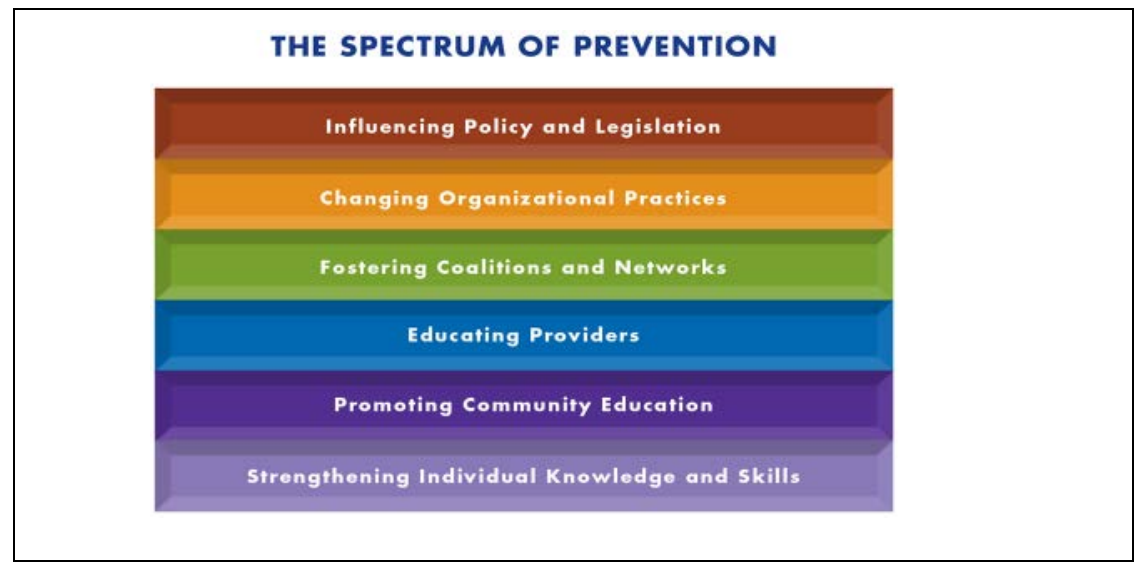

Figure 2. Schematic presentation of the spectrum of prevention model (Cohen \& Swift, 1990). 
Tables 
Table 1. Social-Ecological Model of Sexual Harm Prevention

(Smallbone \& Rayment-McHugh, 2013).

\begin{tabular}{|c|c|c|c|}
\hline Targets & Primary prevention & Secondary prevention & Tertiary prevention \\
\hline Offenders & $\begin{array}{ll}\text { - } & \text { General } \\
\text { deterrence } \\
\text { - } & \text { Developmental } \\
& \text { prevention }\end{array}$ & $\begin{array}{l}\text { - Interventions with } \\
\text { at-risk children } \\
\text { and adolescents }\end{array}$ & $\begin{array}{l}\text { - } \text { Early detection } \\
\text { - Sex offender } \\
\text { treatment groups }\end{array}$ \\
\hline Victims & 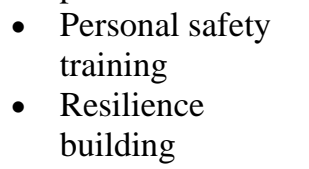 & $\begin{array}{l}\text { - Resilience } \\
\text { building with at- } \\
\text { risk children and } \\
\text { youth }\end{array}$ & $\begin{array}{ll}\text { - } & \text { Ameliorating } \\
& \text { harm } \\
\text { - } & \text { Preventing } \\
& \text { revictimization }\end{array}$ \\
\hline Situations & $\begin{array}{ll}\text { - } & \text { Opportunity } \\
\text { reduction } \\
\text { - } \\
\text { Extended } \\
\text { guardianship }\end{array}$ & $\begin{array}{l}\text { - Situational } \\
\text { interventions in } \\
\text { at-risk places }\end{array}$ & $\begin{array}{l}\text { - } \text { Safety plans } \\
\text { - Organizational } \\
\text { interventions }\end{array}$ \\
\hline Communities & $\begin{array}{l}\text { - Community } \\
\text { education } \\
\text { - Community } \\
\text { capacity building }\end{array}$ & $\begin{array}{l}\text { - Responsible } \\
\text { bystander training } \\
\text { - Enabling } \\
\text { guardianship }\end{array}$ & $\begin{array}{l}\text { - Interventions with } \\
\text { "problem" } \\
\text { families, peers, } \\
\text { organizations, and } \\
\text { communities } \\
\end{array}$ \\
\hline
\end{tabular}


Table 2. The Adaption of Braun and Clarke (2006) Phases of Thematic Analysis Used in the Current Study.

\begin{tabular}{|c|c|c|c|}
\hline Phase & & $\begin{array}{l}\text { Description of process (Braun \& Clarke, } \\
\text { 2006) }\end{array}$ & Description of process (current research) \\
\hline 1. & $\begin{array}{l}\text { Familiarising yourself with the } \\
\text { data }\end{array}$ & $\begin{array}{l}\text { Transcribing data (if necessary), reading } \\
\text { and rereading the data, noting down initial } \\
\text { ideas. }\end{array}$ & $\begin{array}{l}\text { Notes were revised by the research team } \\
\text { within } 48 \text { hrs of the research taking place. } \\
\text { The note-takers at each table reviewed their } \\
\text { notes, critiqued them, and verified them } \\
\text { with the small group participants where } \\
\text { necessary; these notes were then shared, } \\
\text { discussed, and agreed by the wider research } \\
\text { team. This meant that we had a well- } \\
\text { developed, coherent, and fit for purpose } \\
\text { data set. In addition, we had also reread and } \\
\text { reviewed the notes starting to develop initial } \\
\text { ideas. }\end{array}$ \\
\hline 2. & Generating initial codes & $\begin{array}{l}\text { Coding interesting features of the data in a } \\
\text { systematic fashion across the entire data } \\
\text { set, collating data relevant to each other. }\end{array}$ & As outlined. \\
\hline 3. & Searching for themes & $\begin{array}{l}\text { Collating codes into potential themes, } \\
\text { gathering all data relevant to each } \\
\text { potential theme. }\end{array}$ & As outlined. \\
\hline 4. & Reviewing themes & $\begin{array}{l}\text { Checking if the themes work in relation to } \\
\text { the coded extracts (Level 1) and the entire } \\
\text { set (Level 2), generating a thematic "map" } \\
\text { of the analysis. }\end{array}$ & $\begin{array}{l}\text { This happened the same way, but on a } \\
\text { smaller scale. We initially identified a larger } \\
\text { number of themes that we had to edit, } \\
\text { coalesce, and collapse down. This was made }\end{array}$ \\
\hline
\end{tabular}


5. Defining and naming themes

6. Producing the report
Ongoing analysis to refine the specifics of each theme, and the overall story the analysis tells; generating clear definitions and names for each theme.

The final opportunity for analysis. Selection of vivid compelling extract examples, final analysis to the research questions and literature, producing a scholarly report of the analysis. more challenging by the fact that we had top notes and shorthand, not detailed quotes.

We agreed on four coherent themes; the themes made sense individually and in relation to each other. As we had no quotes to draw on, we had to use discussion points as a steering to developing the richness of the data.

No adjustment made. 